\title{
Comparative analysis of complete nucleotide sequence of porcine reproductive and respiratory syndrome virus (PRRSV) isolates in Thailand (US and EU genotypes)
}

\author{
Alongkorn Amonsin*, Roongtham Kedkovid, Suphasawatt Puranaveja, \\ Piya Wongyanin, Sanipa Suradhat and Roongroje Thanawongnuwech
}

Address: Faculty of Veterinary Science, Chulalongkorn University, Henri-Dunant Road, Patumwan, Bangkok 10330, Thailand

Email: Alongkorn Amonsin* - alongkorn.A@chula.ac.th; Roongtham Kedkovid - roongtham_kk@yahoo.com;

Suphasawatt Puranaveja - psuphasawatt@hotmail.com; Piya Wongyanin - p_puns@hotmail.com; Sanipa Suradhat - suradhat.s@chula.ac.th;

Roongroje Thanawongnuwech - roongroje.t@chula.ac.th

* Corresponding author

Published: 16 September 2009

Virology Journal 2009, 6:143 doi:10.1186/1743-422X-6-143

This article is available from: http://www.virologyj.com/content/6///143

(C) 2009 Amonsin et al; licensee BioMed Central Ltd.

This is an Open Access article distributed under the terms of the Creative Commons Attribution License (http://creativecommons.org/licenses/by/2.0), which permits unrestricted use, distribution, and reproduction in any medium, provided the original work is properly cited.

\begin{abstract}
Background: Porcine reproductive and respiratory syndrome virus (PRRSV) is a causative agent of Porcine Reproductive and Respiratory Syndrome (PRRS). In this study, the complete nucleotide sequences of the selected two Thai PRRSV isolates, EU (OICBI) and US (0INPI) genotypes were determined since both isolates are the Thai prototypes.
\end{abstract}

Results: $0|C B|$ and OINPI contain I4,943 and I5,4I2 nucleotides, respectively. The viruses compose 2 untranslated regions (5' UTR and 3' UTR) and 8 open reading frames (ORFs) designated as ORFIa, ORFIb and ORF2-7. Phylogenetic analysis of full length of the viruses also showed that the $0 I C B I$ and OINPI were grouped into the EU and US genotype, respectively. In order to determine the genetic variation and genetic relatedness among PRRSV isolates, the complete nucleotide sequences of PRRSV isolated in Thailand, OICBI and OINPI were compared with those of 2 EU strains (Lelystad, and EuroPRRSV), 6 US strains (MLV, VR2332, PA8, I6244B, SP and HUN4). Our results showed that the OICBI genome shares approximately 99.2\% (Lelystad) and 95.2\% (EuroPRRSV) nucleotide identity with EU field strains. While, the 0INPI genome has $99.9 \%$ nucleotide identity with a live vaccine strain (MLV) and $99.5 \%$ and $98.5 \%$ nucleotide identity with 2 other US isolates, VR2332 and 16244B, respectively. In addition, ORF5 nucleotide sequences of 9 PRRS viruses recovered in Thailand during 2002-2008 were also included in this study. Phylogenetic analysis of ORF5 showed high similarity among EU and US genotypes of the recent Thai PRRS viruses (2007-2008 viruses) with 0ICBI and 0INPI.

Conclusion: Overall, the results suggested that the Thai EU isolate $(0 I C B I)$ may evolve from the EU prototype, Lelystad virus, whereas the Thai US isolate (OINPI) may originate and evolve from the vaccine virus or its derivatives. Interestingly, the US-MLV vaccine was not available in the Thai market in 200I. The Vaccine-like virus might have persisted in the imported pigs or semen and later spread in the Thai swine industry. This report is the first report of complete nucleotide sequences of the Thai PRRS viruses both EU and US genotypes. 


\section{Background}

Porcine reproductive and respiratory syndrome virus (PRRSV) belonging to the genus Arterivirus in the family Arteriviridae in the order Nidovirales is a major swine virus causing economic losses in the swine industry worldwide including Thailand. Porcine reproductive and respiratory syndrome (PRRS) was first evident in the North American countries in 1987 and later in the European countries in 1990 [1]. In Thailand, PRRSV was first isolated in 1996 [2] but was serologically evident since 1989. Our previous report demonstrated that in Thailand both US and EU genotypes exist and sequential analysis of ORF5 gene confirmed genetic variation of Thai PRRS viruses [3].

Full-length genome sequences of PPRSV are essential and have been used for gene functional study, pathogenesis study, and evolutionary study as well as vaccine development of the virus. Full-length sequences of several PRRSV both US and EU genotypes are available in the public database. For example, the US prototype (VR2332) [4] and European prototype (LV) [5] are well characterized. The US genotype strains including the US field strains (16244B) [6], the US-MLV vaccine (MLV) [7], Canadian field strain (PA8) [8], Asian vaccine strain (SP) [9] and Asian field strain (BJ-4 and HUN4) [10] are available in the database. In addition, full-length sequences of EU genotype strain (EuroPRRSV) [11] was also identified. Phylogenetic analysis and full-length sequence comparison of the prototype viruses revealed that US and EU strains share approximately 63\% nucleotide homology [6]. It has been known that ORF1a is relatively high variable, while ORF1b is more conserved among US and EU genotypes. Recent example is that the variation of ORF1a (multiple deletions in Nsp2 region) related to atypical virulence of PRRS in China $[10,12]$. The structural protein encoding genes (ORFs2-7) are 20\% (3 kb) in length of the genome. Out of 6 structural genes, ORF5 and ORF7 have been widely characterized and used to study the genetic diversity of the viruses in several reports [13-17]
In this present study, we described the genetic comparison of full-length sequences of two Thai PRRSV prototypes of both EU (01CB1) and US (01N1) genotypes. ORF5 nucleotide sequences of 9 PRRS viruses recovered during 20022008 were also included in the analysis. Overall, 01CB1 closely related to the Lelystad virus (99.2\%) and EuroPRRSV (95.2\%). On the other hand, the 01NP1 genome was similar to the US-MLV, VR2332 and 16244B at 99.9\%, 99.5\% and 98.5\% identity, respectively. The availability of complete genome sequences of Thai PRRSV is essential and useful for the evolution study of PRRSV as well as the development of infectious clones or vaccines in the future.

\section{Results}

\section{Complete genome of Thai PRRS viruses}

During the 2001 PRRS outbreaks in Thailand, the PRRS viruses, $01 \mathrm{CB} 1$ and $01 \mathrm{NP} 1$ were isolated from the intensive swine farming areas. Additional 9 PRRS viruses isolated in Thailand from 2002-2008 were also included in the study (Table 1). To study the relationship and genetic characteristics of those Thai viruses, two isolates, "01CB1 and 01NP1", considering the Thai prototypes were selected for full-length genome sequencing since the pathogenicity of both viruses were previously studies. The viruses were identified as the EU (01CB1) and the US (01NP1) strains based on ORF 5 analysis [3]. In this study, we have elucidated the full-length sequences of PRRSV of 01CB1 containing 14,943 bp (52.67\%GC) and $01 \mathrm{NP} 1$ containing 15,412 bp $(52.76 \% \mathrm{GC})$. The viruses had untranslated regions (5' UTR and 3' UTR) and 8 open reading frames (ORFs) designated as ORF1a, ORF1b and ORF2-7. The details of genome organization of PRRS viruses, 01CB1 and 01NP1, were shown in table 2.

\section{Phylogenetic analysis}

Phylogenetic analysis of the viruses showed that 01CB1 and $01 \mathrm{NP} 1$ were grouped into the separated lineages represented by the EU (LV and EuroRRSV) and US (MLV,

Table I: List of PRRSV analyzed in this study

\begin{tabular}{|c|c|c|c|c|}
\hline Virus ID & Location & Year of isolation & Strain & GenBank accession number \\
\hline OICBI & Chonburi & 2001 & EU & DQ864705* \\
\hline OINPI & Nakhon Pathom & 2001 & US & $\overline{\mathrm{DQ} 056373^{*}}$ \\
\hline $02 S B 3$ & Saraburi & 2002 & EU & F) 908074 \\
\hline $08 R B I 03$ & Ratchaburi & 2008 & EU & F) 908075 \\
\hline 08NPI44 & Nakhon Pathom & 2008 & EU & Fj908076 \\
\hline 07NP4 & Nakhon Pathom & 2007 & US & Fj908077 \\
\hline 08NP|47 & Nakhon Pathom & 2008 & US & Fj908078 \\
\hline 08NP|48 & Nakhon Pathom & 2008 & US & Fj908079 \\
\hline 08RB5I & Ratchaburi & 2008 & US & F) 908080 \\
\hline $08 R B I 54$ & Ratchaburi & 2008 & US & Fj908081 \\
\hline $08 R B \mid 60$ & Ratchaburi & 2008 & US & F) 908082 \\
\hline
\end{tabular}

* nucleotide sequences of full length viruses 
Table 2: Genome organization of PRRS viruses, OICBI and OINPI, in this study

\begin{tabular}{|c|c|c|c|c|c|c|c|}
\hline \multirow[t]{3}{*}{ ORFs } & \multicolumn{3}{|c|}{ O ICB I } & \multicolumn{3}{|c|}{ OINPI } & \multirow[t]{3}{*}{ Protein* } \\
\hline & \multicolumn{2}{|c|}{ Nucleotides } & \multirow{2}{*}{$\begin{array}{l}\text { Amino acid } \\
\text { Size }\end{array}$} & \multicolumn{2}{|c|}{ Nucleotides } & \multirow{2}{*}{$\begin{array}{l}\text { Amino acid } \\
\text { Size }\end{array}$} & \\
\hline & Position & Size & & Position & Size & & \\
\hline 5' UTR & $1-144$ & 144 & - & $1-189$ & 189 & - & - \\
\hline ORFIa & $145-7335$ & 7191 & 2396 & $|90-770|$ & 7512 & 2503 & $\begin{array}{l}\text { Replicase polyprotein; Nsplalpha, beta (Papain-like cysteine } \\
\text { protease); Nsp2 (cystein protease); Nsp3 - } 8\end{array}$ \\
\hline ORFIb & $7317-11708$ & 4392 & 1463 & $7680-|207|$ & 4392 & 1463 & RNA dependent RNA polymerase (Nsp 9 - 12) \\
\hline ORF2 & $11719-12468$ & 750 & 249 & $|2073-| 2843$ & 771 & 256 & GP2 envelop protein \\
\hline ORF3 & $12327-13124$ & 798 & 265 & $12696-13460$ & 765 & 254 & GP3 envelop protein \\
\hline ORF4 & $12869-13420$ & 552 & 183 & $|324|-\mid 3777$ & 537 & 178 & GP4 envelop protein \\
\hline ORF5 & $134|7-| 4022$ & 606 & 201 & $13788-14390$ & 603 & 200 & GP5 envelop protein \\
\hline ORF6 & $|40| 0-|453|$ & 522 & 173 & $|4375-| 4899$ & 525 & 174 & Matrix protein \\
\hline ORF7 & $|452|-\mid 4907$ & 387 & 128 & |4889-|5260 & 372 & 123 & Nucleocapsid protein \\
\hline 3'UTR & $|4908-| 4943$ & $36 * *$ & - & $1526|-154| 2$ & 152 & - & - \\
\hline
\end{tabular}

*Protein functions were identified based on Blast-P results and Wootton et al., 2000

*** Poly $A$ tail of $0 I C B I$ was not identified in this study

VR2332, 16244B, PA8, SP and HUN4) isolates (Fig. 1). The 01CB1 was the most closely related to the $\mathrm{LV}$ virus (EU prototype), while the 01NP1 was the most closely related to the US MLV strain and the US prototype (VR2332). In general, phylogenetic analysis of full length sequences of PRRSV indicated that the Thai viruses were of both US and EU origin and exhibited the highest sequence similarity to those of EU prototype (LV) and the US prototype (MLV), respectively (Table 3). Phylogenetic analysis of ORF5 sequences of recent Thai PRRSV (2002-2008) were also analyzed, the results also showed high similarity among EU and US genotypes of the recent Thai PRRS viruses (2007-2008 viruses) with 01CB1 and 01NP1 (Fig 2). In addition, all EU isolates from Thailand (01CB1, 02SB3, 08RB103, 08NP144) are clustered into the EU genotype - subtype 1, which is the common subtype for EU-PRRSV worldwide as well as the EU vaccine strains.

\section{Genetic analyses}

Pair-wise sequence comparisons of full-length sequences of the Thai isolates are presented in table 3 . The two Thai isolates were compared with eight representative PRRS viruses of both genotypes obtained from the GenBank database that had been completely sequenced. The 01CB1 displayed the highest percentage of nucleotide identity to the EU isolates (LV and EuroPRRSV), while the 01NP1 had high percentage of similarity to the US isolates (MLV, VR2332, 16244B, PA8, SP, HUN4) with more than 98\% nucleotide identity. However, the percent homology between the two Thai isolates, 01CB1 and 01NP1, was $59.81 \%$.

In this study, 5' UTR of 01NP1 and 01CB1 had $189 \mathrm{bp}$ and $144 \mathrm{bp}$ in length. 5'UTR of 01CB1 was almost identical to the 5'UTR of VR2332 (99.5\%) and the US-MLV (98.6\%) (data not shown), while 5' UTR of 01NP1 displayed profound nucleotide sequence identity (more than 90\%) with the US isolates. Similar findings were also observed in 3' UTR that 01CB1 and 01NP1 shared high percentage of nucleotide identity of 3' UTR of the EU and US genotypes.

Table 3: Pair-wise sequence comparison of full-length nucleotide sequences of PRRSV from Thailand and those of EU and US strains

\begin{tabular}{lllllllllll}
\hline \multicolumn{1}{c}{ Pair-wise sequence comparison of PRRS viruses } \\
(\% nucleotide identity)
\end{tabular}

* Sequence comparison of PRRSV in this study was based on ORFI-ORF7 sequences. 


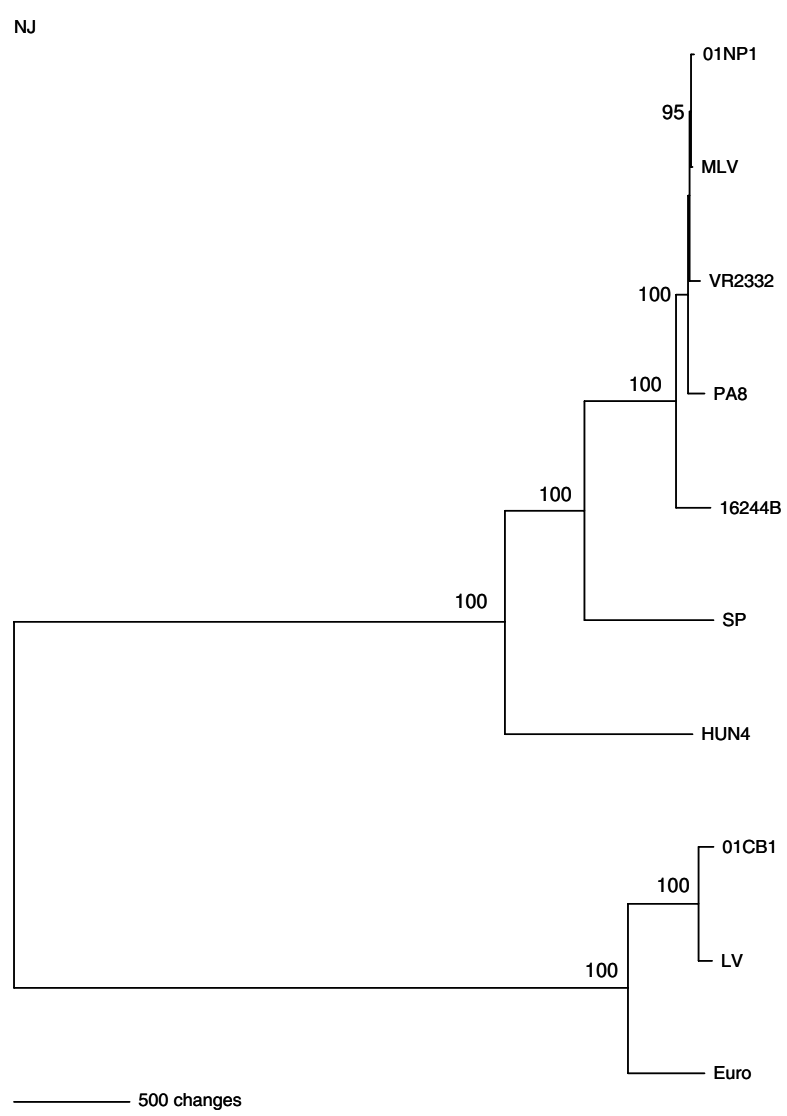

Figure I

Phylogenetic relationship of PRRS viruses, full length genome Sequences. Whole genome sequences of ORFIORF7 were used for phylogenetic analysis using PAUP program applying $\mathrm{NJ}$ algorithm with distance setting of total character difference. Bootstrap analysis was conducted with I000 replication.

ORF1a and ORF1b of 01CB1 and 01NP1 encoded proteins of 2,396 and 1,463 and 2,503 and 1,463 amino acids, respectively. ORF1a and ORF1b of 01CB1 were similar to those of the EU strains (99.2\% and 99.3\%) (data not shown). Comparison of deduced amino acids revealed that ORF1a had more polymorphic sites than ORF1b proteins. Polymorphic sites in ORF1a of 01CB1 and $01 N P 1$ were $125 / 2396$ and $61 / 2503$. On the other hand, polymorphic amino acids in ORF1b were 27/1463 (01CB1) and 16/1463 (01NP1). These findings indicated that ORF1a was continuously changing and evolving as previously described especially in the Nsp2 region [8]. In this study, deduced amino acids of the Nsp2 proteins of 01NP1 were compared to those of US strains (MLV, VR2332, PA8, 16244B, SP and HUN4) (Fig 3). Amino acid deletions were found at position 482 ( $1 \mathrm{aa}$ ) and 533561 (28 aa) in Nsp2 of the Chinese isolate (HUN4) but not in other US strains. Thirty six amino acid insertions were also observed in the Asian vaccine strain (SP), but not found in 01NP1 Thai isolate.

ORFs2-7 genes encoded structural proteins of the PRRSV including envelop protein (ORF2-5), matrix protein (ORF 6 ) and nucleocapsid protein (ORF 7). Structural genes of $01 \mathrm{CB} 1$ and $01 \mathrm{NP} 1$ were approximately $3 \mathrm{~kb}$ in size. In this study, ORF 2-7 of the two viruses were conserved (less polymorphic sites). ORF 2-7 of 01CB1 and 01NP1 were similar to ORF2-7 of the LV and the US-MLV viruses ( $>99.0 \%$ identity) (Data not shown). Out of 5 structural genes (ORFs2-7), ORF 7 was highly conserved in both EU and US strains, while ORF5 was less conserved among both strains. Deduced amino acids of ORF5 gene of 01NP1 and 01CB1 and additional 9 PRRSV (2002-2008) were compared to those of US strains (MLV, VR2332, PA8, 16244B, SP and HUN4) and EU strain (LV and EuroPRRSV) (Fig 4 and 5). The results showed that the US strains (01NP1) had 11 polymorphic sites comparing to US consensus and the EU strains (01CB1) had 13 polymorphic sites comparing to the EU consensus (Fig 4 and 5). Interestingly, polymorphic sites in ORF5 of EU strains were found more than those of US strains. Sequence distances of ORF5 among PRRS viruses are 82.0-99.5\% (among US genotype) and 84.7-99.5\% (among EU genotype). These findings indicated moderate genetic diversity among Thai PRRSV in both genotypes.

In summary, genetic analyses of untranslated region $\left(5^{\prime}\right.$ UTR and 3' UTR) and ORF 1-7 showed that 01CB1 was mostly similar to the EU prototype, LV (98.5\% -99.7\%). The Thai US strain, $01 \mathrm{NP} 1$ was closely related to the USMLV vaccine strain (99.4\%-100\%).

\section{Discussion}

In this study, we reported full-length sequences of the Thai PRRS viruses of both EU (01CB1) and US (01NP1) genotypes. The full-length size of the EU strain, 01CB1, is $14,943 \mathrm{bp}$, similar to the two EU strains (LV; $15,101 \mathrm{bp}$ and EuroPRRSV; $15,047 \mathrm{bp}$ ) [5,11]. On the other hand, $01 \mathrm{NP} 1$ isolate has $15,412 \mathrm{bp}$ in size. The size of this virus is similar to the US strains (VR2332, 15,411 bp and $16244 \mathrm{~B}, 15,411 \mathrm{bp}$ ) $[4,6]$, the US-MLV vaccine (MLV, 15,412 bp) [7], Canadian field strain (PA8, 15,411 bp) [8], Asian vaccine strain (SP, 15,520 bp) [9] and Asian field strain (BJ-4, 15,410 bp and HUN4, $15352 \mathrm{bp)} \mathrm{[10].}$

Genome organization of the Thai PRRS viruses contained 8 open reading frames. Two non structural genes, ORF1a and ORF1b, composed $70 \%$ in size of the genome. ORF1a and ORF1b encoded replicase polyproteins, which subsequently cleaved to 13 subunits (Nsp1a/b-Nsp12). ORF27 were structural genes that encode envelop protein (ORF2-5), matrix protein (ORF 6) and nucleocapsid pro- 


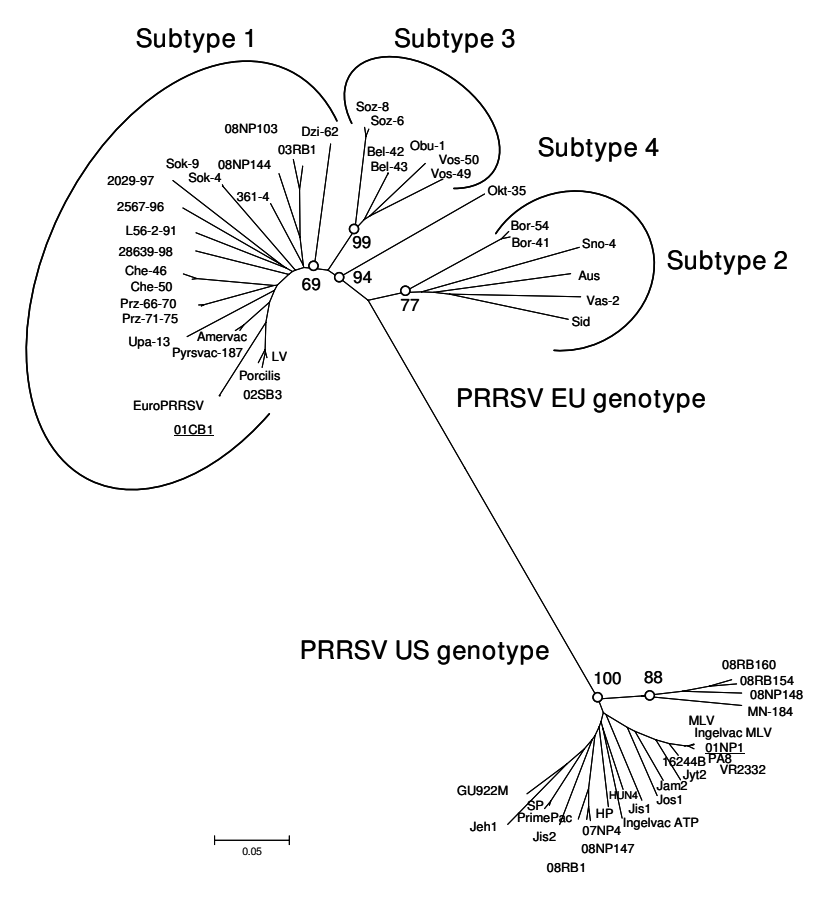

Figure 2

Phylogenetic relationship of PRRS viruses, ORF 5 sequences. ORF5 sequences were used for phylogenetic analysis using MEGA program applying $\mathrm{NJ}$ algorithm with Kimura 2-parameter. Bootstrap analysis was conducted with 2000 replication.

tein (ORF7) [8]. Most full-length sequences of PRRSV had identified of 8 ORFs in the genome, however some studies have reported additional ORF2 (ORF2a and ORF2b) encoding unknown protein function.

Comparison of full-length sequences of the Thai PRRS viruses (01CB1 and 01NP1) with other PRRS viruses from the European, north American and Asian countries revealed that $01 \mathrm{CB} 1$ virus was similar to the EU strains especially the EU prototype, Lelystad (99.2\%). Unexpectedly, 01NP1 had nucleotide sequences similar to the USMLV (99.9\%) and the US-prototype (VR2332) (99.5\%). Phylogenetic analysis showed that 01CB1 and 01NP1 were clustered into the EU and the US lineages, respectively. 01CB1 was closely related to the LV virus, the EU prototype whereas, 01NP1 was closely related to the USMLV (vaccine strain) and VR2332 (US prototype). Our results indicated that the Thai EU strain evolved from the LV. The introduction of the Thai EU strain of PRRSV may possibly due to the importation of persistently infected pigs or semen. Interestingly, $01 \mathrm{NP} 1$ was closely related to the US-MLV vaccine strain. Since the US-MLV vaccine was not available in Thailand until 2005, the contaminated vaccine-like virus might have persisted in the imported pigs or semen at that time. Our previous report found that the Thai EU isolates were closely related to the Danish viruses and the Thai US isolates were closely related to the Canadian viruses [3]. Since the US-MLV has been found in the Danish pig population [18] at the same time of the first PRRSV report in Thailand [2]. 01NP1 might originate from persistently US-MLV infected imported pigs either from Canada or Denmark. Similarly, the evidence of the field strain (PA8) that originated and evolved from the US-MLV vaccine strain (RespPRRS) had been documented in Canada [8]. Unfortunately, full length nucleotide sequence of the Spanish vaccine virus (Amervac) was not available for analysis since only the Spanish vaccine was the only live vaccine available at that time. The analysis will rule out the possibility that the Thai EU strain may also evolve from imported Spanish vaccine strains in the 90 s.

In this study, the most variable ORFs were ORF1a (Nsp2) and ORF5. Both ORF1a and ORF5 were previously reported as highly variable regions. ORF1a (Nsp2 subunit) can be used as genetic marker for monitoring the mutation or genetic changes as well as for differential diagnosis of PRRS viruses [9,19,20]. Recently, atypical PRRS outbreaks have been reported in China since 2006 causing severe economic losses in the Chinese swine industry. Genome analysis of the Chinese viruses revealed that the viruses contain 2 distinct amino acid deletions in the Nsp2 gene indicating highly virulent of PRRS viruses $[10,12]$. The multiple deletions in this specific Nsp2 region reported in the Chinese isolates causes the socalled 'Swine high fever syndrome' [10]. The pathogenesis of turning virulence of the Chinese viruses is still unclear and needed to be elucidated. Fortunately, we did not see any deletion in our Thai isolates similar to the Chinese viruses.

Similar to other studies, the variation of ORF5 region can be applied for identification and differentiation of the PRRSV. In addition, ORF5 can also be used for the study of genetic diversity of the viruses $[3,17,21,22]$. In this study, 9 additional PRRS viruses were analyzed in the ORF5 region. Phylogenetic analysis of ORF5 clearly separated US genotype and EU genotype, which both genotypes can be found circulating in Thailand (Fig 2). It has been known that the US genotype is more diverse than the EU genotype. However, in this study, all Thai EU-genotype isolates are more diverse and belonged to the EU genotype-Subtype 1, similar to some European isolates (The Netherlands, Denmark, Spain, Poland and Italy) but not the PRRSV from Eastern European which are belonged to EU genotype-Subtype 2, 3 and 4 (Belarus and Lithuania) [23]. Currently, both EU and US genotypes are still circulating in the Thai swine industry with predominantly the US genotype (data not shown). Interestingly, our results 
indicated that all Thai PRRS viruses in this study had evolved from the Thai PRRSV prototypes of both genotypes. No evidence of recent imported new PRRSV strains was found in this study possibly due to the Department of Livestock Development, Thailand do not allow the importation of PRRSV-positive animals.

\section{Conclusion}

In conclusion, our study provided full-length genome sequences of the Thai PRRS viruses of both genotypes. The genetic and cluster analysis of the Thai PRRSV of the EU genotype (01CB1) may evolve from the EU prototype, the Lelystad virus. On the other hand, the Thai PRRSV of the US genotype (01NP1) may originate and evolve from the US-MLV vaccine virus or its derivatives. It should be noted that ORF1a (Nsp2) and ORF5 contained highly variable regions and can be used as diagnostic markers for prevention and control of newly emerged PRRSV. This work highlights the significance of full-length sequences of PRRSV in Thailand for future studying of the genesis and evolution of the PRRS viruses.

\section{Methods \\ PRRS viruses}

The Thai EU isolate (01CB1) used in this study was isolated from the nursery pigs having PRDC problem in Chonburi province, the Eastern region of Thailand in 2001. The EU PRRSV caused reproductive failure in a 3,000 sow herd and later the respiratory disease with moderate morbidity and mortality in the nursery pigs. The Thai US isolate (01NP1) was isolated in Nakhon Pathom province located in the central region of Thailand in the same year from the nursery pigs in a 2,000 sow herd with more than $10 \%$ loss after weaning. Both farms are practicing a continuous-flow system and piglets are weaned weekly. The pathogenesis study of the $01 \mathrm{CB} 1$ and the $01 \mathrm{NP} 1$ virus was done and the $01 \mathrm{CB} 1$ was identified as a low virulence strain while the 01NP1 was identified as a high virulence strain. Based on ORF5 sequence analysis, $01 \mathrm{CB} 1$ and $01 \mathrm{NP} 1$ were characterized and grouped in the EU and the US genotypes respectively [3]. Additional 9 PRRS viruses isolated in Thailand from 2002-2008 were included in the study (Table 1$)$. The viruses were later identified as EU genotype $(n=3)$ and US genotype $(n=6)$ based on ORF5 nucleotide sequencing and then include in the phylogenetic analysis.

\section{Virus isolation}

Virus isolation was done from the lung tissues as previously described [24]. The cell culture-adapted viruses were propagated in MARC-145 cells in minimum essential medium (MEM) (Hyclone, USA) with 5\% fetal calf serum (FCS) (Hyclone, USA) for 3 passages. Immunoperoxidase monolayer assay (IPMA) using SDOW-17 was used to confirm the presence of PRRS virus [3]. The virus concen- tration of $10^{3} \mathrm{TCID} 50 / \mathrm{ml}$ was used for viral RNA preparation in this study.

\section{Viral RNA and CDNA preparation}

RNA isolation using QIAamp RNA Mini Kit (Qiagen, Hilden, Germany) was done on the stock virus solution following the manufacture's instruction. In brief, $200 \mu \mathrm{l}$ of virus-containing supernatant was mixed with $200 \mu \mathrm{l}$ buffer AVL and incubated for 10 minutes. Then, $500 \mu \mathrm{l}$ of ethanol was added to the mixture. The mixture was then transferred to QIAamp spin column and centrifuged at $8000 \mathrm{rpm}$ for $2 \mathrm{~min}$. The spin column was subsequently washed with $500 \mu \mathrm{l}$ of buffer AW1 and AW2 and centrifuged at $8000-14000 \mathrm{rpm}$ for $3 \mathrm{~min}$. Finally, $50 \mu \mathrm{l}$ of buffer AVE was added and centrifuged at $8000 \mathrm{rpm}$ for 3 min to elute viral RNA. cDNA synthesis was then performed by incubating viral RNA with $0.5 \mu \mathrm{g}$ Random primers (Promega, Madison, WI) at $70^{\circ} \mathrm{C}$ for $5 \mathrm{~min}$ and then $4^{\circ} \mathrm{C}$ for $5 \mathrm{~min}$. The mixture was then added with $1 \times$ Improm-II reaction buffer (Promega), $0.5 \mathrm{mM}$ dNTPs (Fermentus), $2.5 \mathrm{mM} \mathrm{MgCl}$ (Promega), $10 \mathrm{U}$ of Rnasin Ribonuclease inhibitor (Promega) and $1 \mu$ l of Improm-II Reverse Transcriptase. The mixture was incubated in thermal cycler at $25^{\circ} \mathrm{C}$ for $5 \mathrm{~min}, 42^{\circ} \mathrm{C}$ for $60 \mathrm{~min}$ and $70^{\circ} \mathrm{C}$ for $15 \mathrm{~min}$.

\section{PRRSV genome sequencing}

Oligonucleotide primers used in this study were designed based on sequence information of the EU and US prototypes, LV and VR2332, respectively. Additional primers were designed for gap closure to complete whole genome sequences of the viruses. Sequence information of each oilgonucleotide primers are provided in additional file 1 . PCR amplification of viral RNA was performed as previously described [3]. In brief, $25 \mu \mathrm{l}$ of PCR reaction was prepared by adding $2 \mu \mathrm{l}$ of $\mathrm{cDNA}, 1 \times$ Eppendrof Master Mix (Eppendrof, Hamburg, Germany) and $0.8 \mu \mathrm{M}$ of oligonucleotide primer. The PCR reaction mixture was incubated in thermal cycler with condition: $95^{\circ} \mathrm{C}$ for $10 \mathrm{~min}$ and 35 cycle of denaturation $\left(95^{\circ} \mathrm{C}\right.$ for $\left.45 \mathrm{Sec}\right)$, annealing $\left(55^{\circ} \mathrm{C}\right.$ for $\left.45 \mathrm{Sec}\right)$, extension $\left(72^{\circ} \mathrm{C}\right.$ for $\left.90 \mathrm{Sec}\right)$, and final extension of $72^{\circ} \mathrm{C}$ for $15 \mathrm{~min}$. The PCR products were then analyzed in $2 \%$ gel electrophoresis (FMC Bioproducts, Rockland, ME). The PCR products were then purified using the Perfectprep Gel Cleanup Kit (Eppendorf,) for further DNA sequencing. The DNA sequencing reaction was performed, using a commercially available kit (Big Dye Terminator V.3.0 Cycle Sequencing Ready Reaction; Foster City, CA), at a final volume of $20 \mu \mathrm{l}$, containing 8 $\mu \mathrm{l}$ of dye terminator and $12 \mu \mathrm{l}$ of specific sequencing primer at the concentration of $3.2 \mathrm{pmol}$. The sequencing products were analyzed with the ABI-Prism 310 Genetic Analyzer (Perkin Elmer, Norwalk, CT). ORF5 nucleotide sequencing was also performed using the oligonucleotides specific for ORF5 and then subjected for DNA 


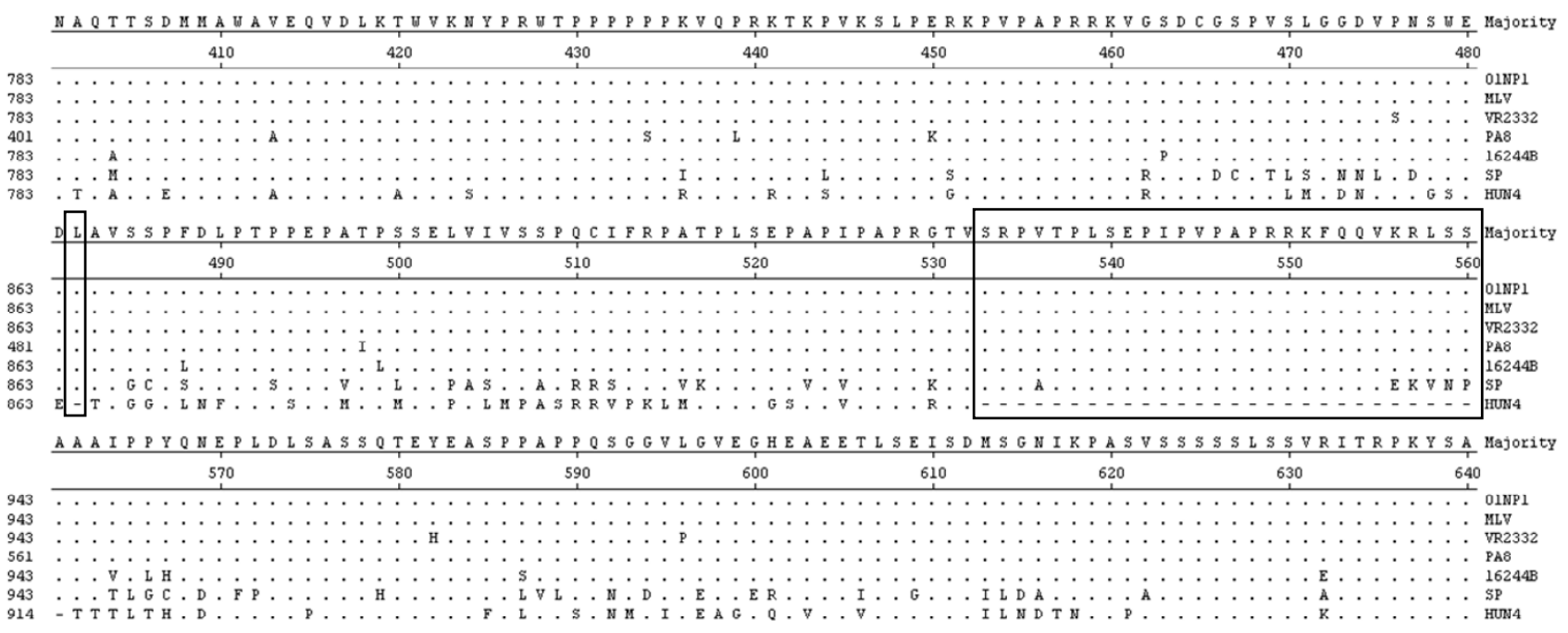

QAIIDSGGPCSGHLOEVKETCLSVMREACDATKLDDPATQEULSRMUDRVDMLTWRNTSVYQAICTLDGRLKFLPKMILEMAJORIT

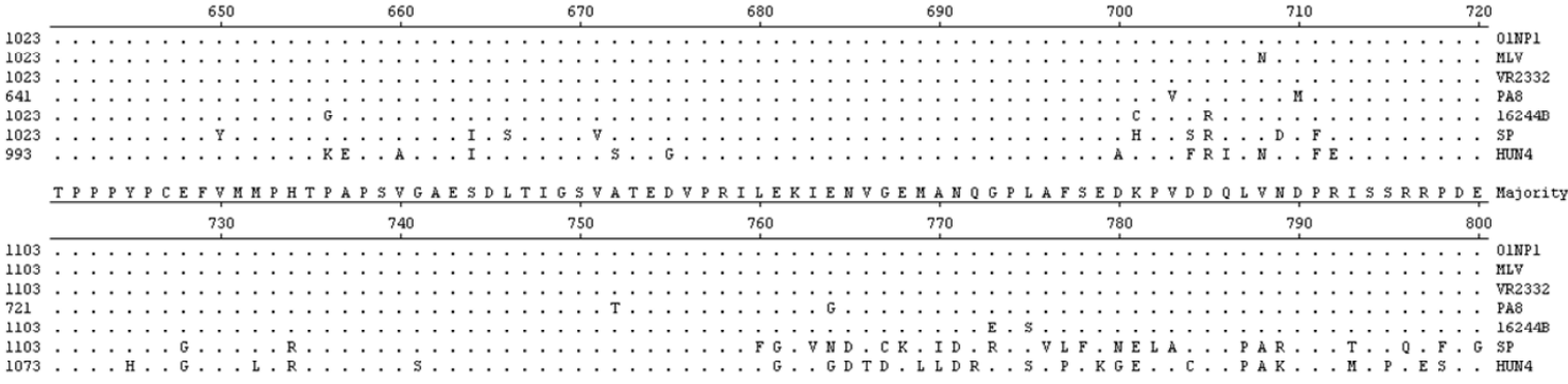

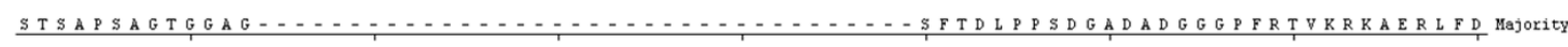

\begin{tabular}{|c|c|c|c|c|c|c|c|}
\hline 310 & 820 & 83 & & 8 & & & 880 \\
\hline
\end{tabular}

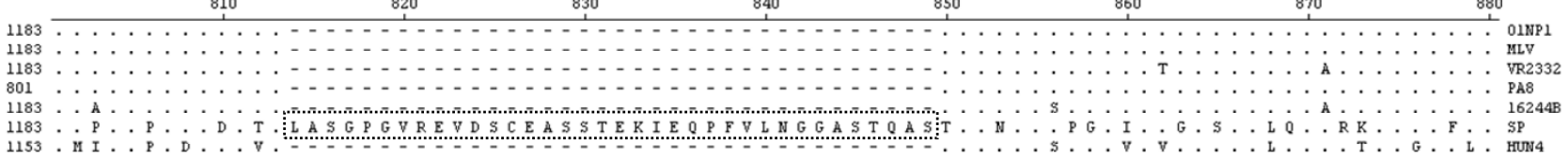

QLSR OVFDLVSHLPVFFSRLFYPGGGYSPGDUGFAAFTLLCLFLCYSYPAFGIAPLLGVFSGSSRRVRUGVFGCULAFAVMAJORITY

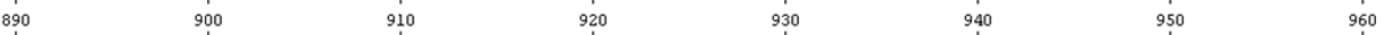

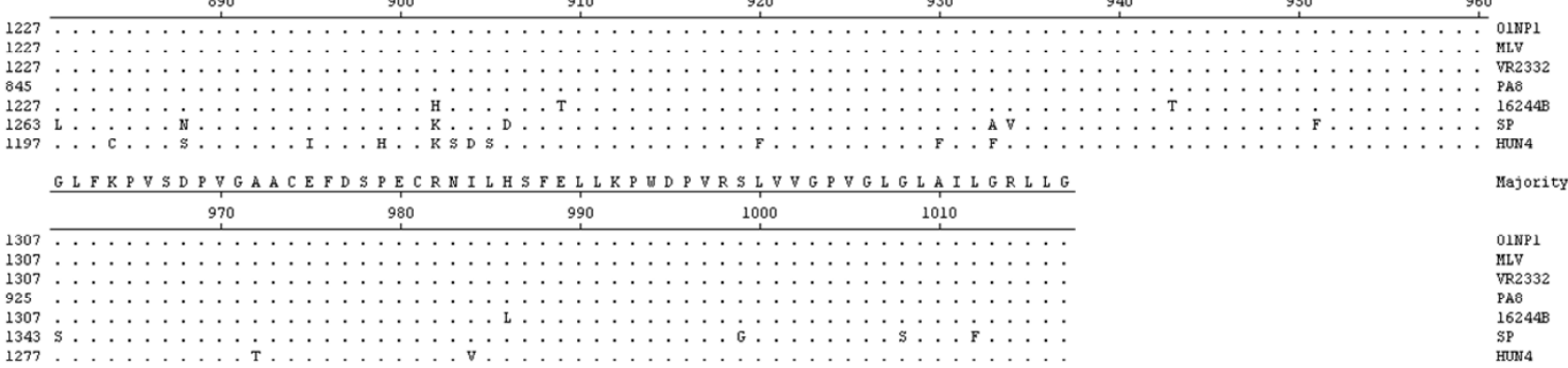

\section{Figure 3}

Sequence alignment of NSP2 of PRRSV viruses (US strains). Deduced amino acids of NSP2 gene of 0INPI were compared to those of US strains (MLV, VR2332, PA8, I6244B, SP and HUN4). No amino acid deletions position 482 and 533-56I were found in most US strain except HUN4 (solid blocks). While 36 amino acid insertions were observed in SP (Asian vaccine strain) (dotted block). 


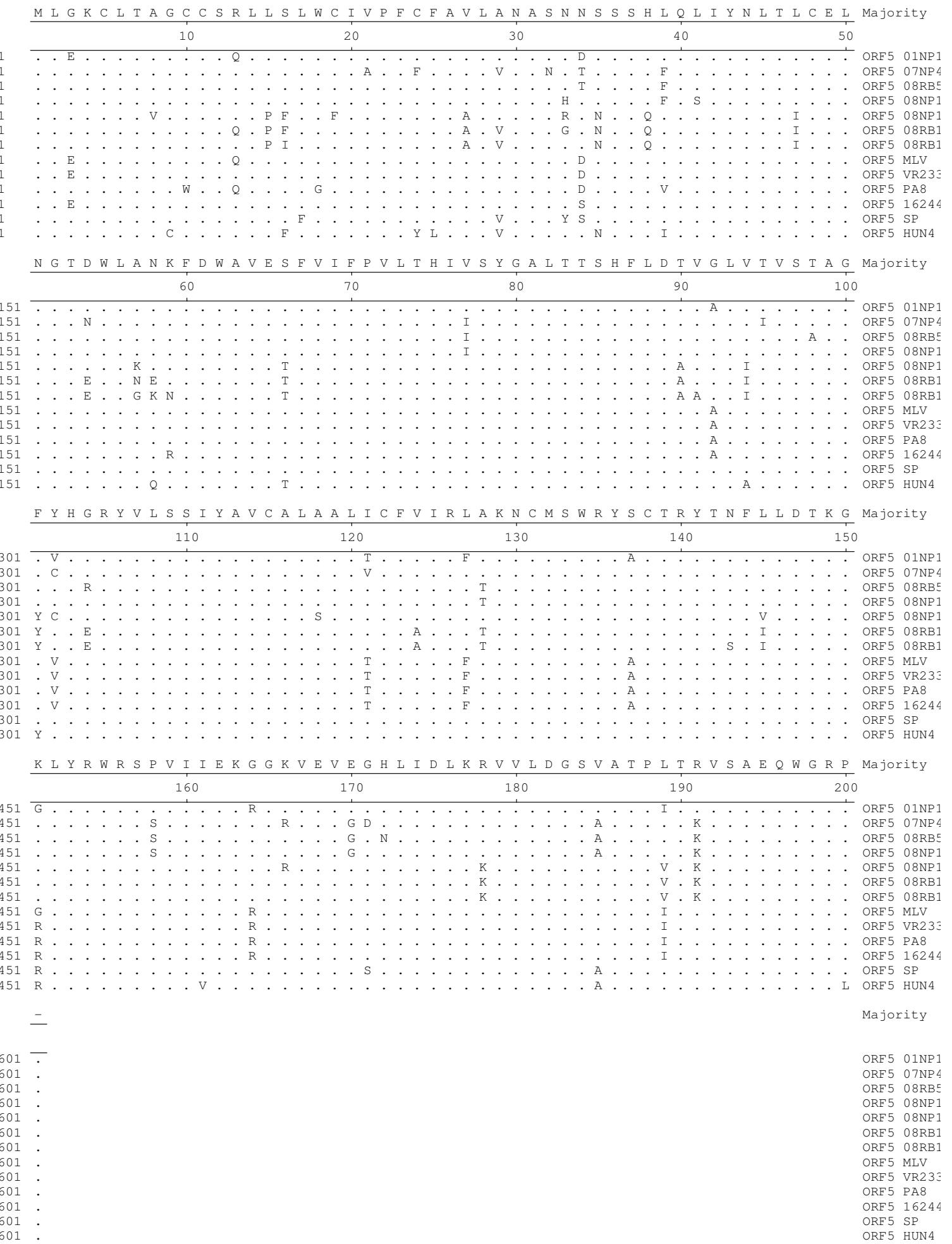

\section{Figure 4}

Sequence alignment of ORF5 of PRRSV viruses (US). Deduced amino acids of ORF5 gene of 0INPI and 6 PRRSV were compared to those of US strains (MLV, VR2332, PA8, I6244B, SP and HUN4). 


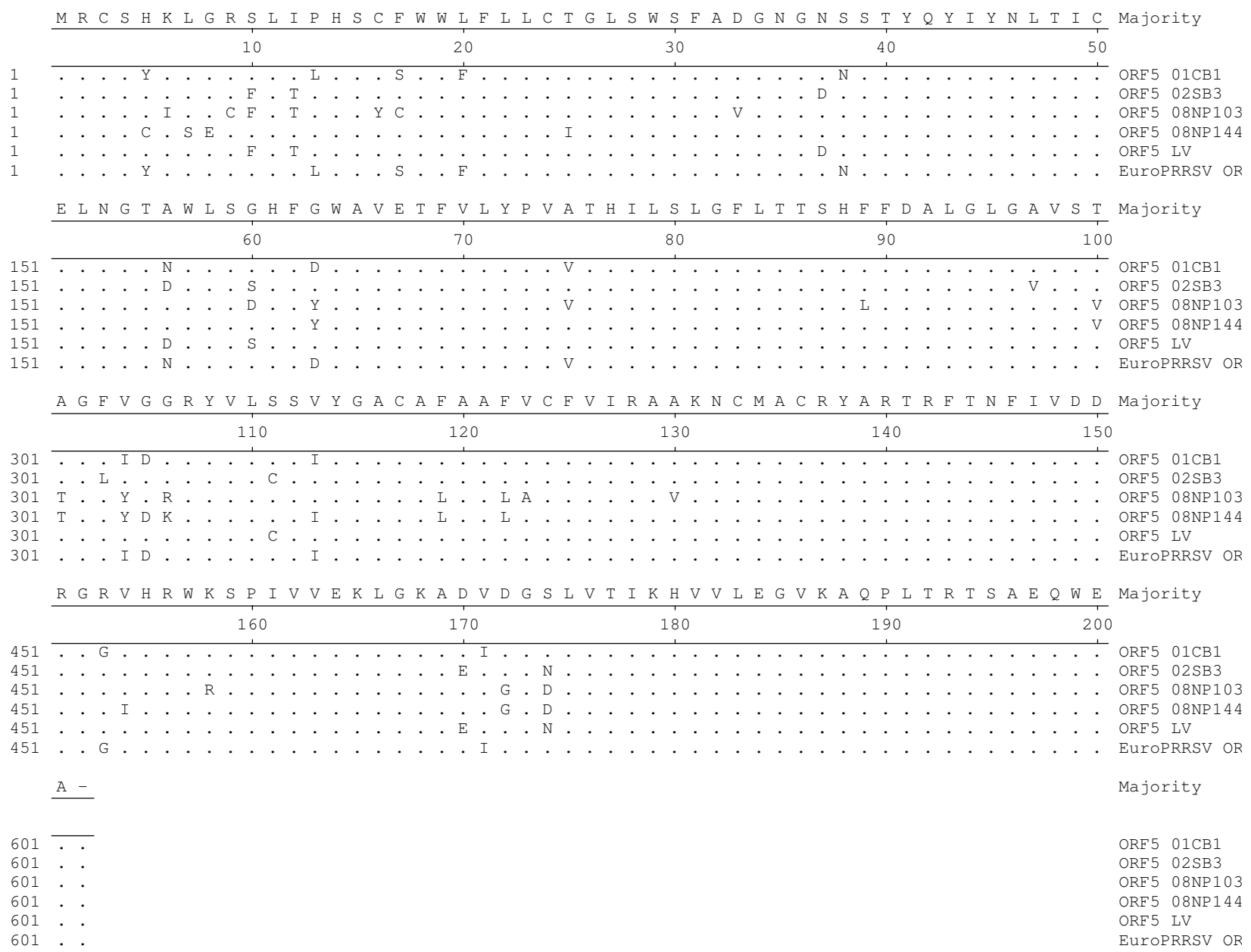

Figure 5

Sequence alignment of ORF5 of PRRSV viruses (EU). Deduced amino acids of ORF5 gene of 0ICBI and 3 PRRSV were compared to those of EU strains (LV and EuroPRRSV).

sequencing. At least 4 coverages of viral nucleotide were performed in the study, to ensure the quality of PRRS genome sequencing.

\section{Analysis of nucleotide and amino acid changes in PRRS viruses}

Genome assembly was conducted by using a computer program SeqMan (DNASTAR, Madison, WI). In this study, the full-length genome sequencing of 2 viruses (01CB1 and 01NP1) was conducted to reach at least 4 time coverages of each virus. In addition, the chromatograms of nucleotide sequences of each PCR products were rechecked and validated to ensure the type and position of nucleotide and amino acid changes in PRRS genome. The sequence alignment and amino acid comparison were done by computer program, MegAlign (DNASTAR). The phylogenetic analysis was performed using the PAUP version 4.0 software (Sinauer Associates, Sunderland, MA) applying NJ algorithm with distance setting of total character difference and the MEGA3 software applying NJ algorithm with Kimura 2- parameter. Bootstrap analysis was conducted with 1000 replications. The nucleotide sequences of the Thai PRRS viruses, 01CB1 and 01NP1 were submitted to the Genbank database under the accession numbers: [01CB1: DQ864705 and 01NP1: DQ056373]. The ORF5 nucleotide sequences of 9 viruses were also in the Genbank database under the accession numbers: [FJ908074-FJ908082].

\section{Competing interests}

The authors declare that they have no competing interests. 


\section{Authors' contributions}

AA carried out experimental design, genome sequencing, genetic and cluster analysis and drafting the manuscript and final approval. RK conducted virology and molecular cluster analysis studies. SP conducted whole genome and gene sequencing studies. PW conducted molecular genetic work. SS and RT participated in virology study and drafting the manuscript. All authors read and approved the final manuscript.

\section{Additional material}

\section{Additional file 1}

Oligonucleotide primers used in the study. List of oligonucleotide primers used in this study.

Click here for file

[http://www.biomedcentral.com/content/supplementary/1743422X-6-143-S1.PDF]

\section{Acknowledgements}

This work was supported by the grant from The Thailand Research Fund MRG4780063 to Dr. Amonsin.

\section{References}

I. Gilbert SA, Larochelle R, Magar R, Cho HJ, Deregt D: Typing of porcine reproductive and respiratory syndrome viruses by a multiplex PCR assay. J Clin Microbiol I997, 35:264-267.

2. Damrongwatanapokin S, Arsayuth K, Kongkrong C, Parchariyanon S, Pinyochon W, Tantaswasdi U: Serological studies and isolation of porcine reproductive and resiratory syndrome (PRRS) virus in Thailand. J Thai Vet Med Assoc 1996, 47:19-30.

3. Thanawongnuwech R, Amonsin A, Tatsanakit A, Damrongwatanapokin S: Genetics and geographical variation of porcine reproductive and respiratory syndrome virus (PRRSV) in Thailand. Vet Microbiol 2004, 101:9-21.

4. Nelsen C], Murtaugh MP, Faaberg KS: Porcine reproductive and respiratory syndrome virus comparison: divergent evolution on two continents. J Virol 1999, 73:270-280.

5. Meulenberg JJ, Petersen den Besten A, de Kluyver E, van Nieuwstadt A, Wensvoort G, Moormann RJ: Molecular characterization of Lelystad virus. Vet Microbiol 1997, 55:197-202.

6. Allende R, Lewis TL, Lu Z, Rock DL, Kutish GF, Ali A, Doster AR, Osorio FA: North American and European porcine reproductive and respiratory syndrome viruses differ in non-structural protein coding regions. J Gen Virol I999, 80(Pt 2):307-3I5.

7. Opriessnig T, Halbur PG, Yoon KJ, Pogranichniy RM, Harmon KM, Evans R, Key KF, Pallares FJ, Thomas P, Meng XJ: Comparison of molecular and biological characteristics of a modified live porcine reproductive and respiratory syndrome virus (PRRSV) vaccine (ingelvac PRRS MLV), the parent strain of the vaccine (ATCC VR2332), ATCC VR2385, and two recent field isolates of PRRSV. | Virol 2002, 76: | | 837- | | 844.

8. Wootton S, Yoo D, Rogan D: Full-length sequence of a Canadian porcine reproductive and respiratory syndrome virus (PRRSV) isolate. Arch Virol 2000, 145:2297-2323.

9. Key KF, Haqshenas G, Guenette DK, Swenson SL, Toth TE, Meng XJ: Genetic variation and phylogenetic analyses of the ORF5 gene of acute porcine reproductive and respiratory syndrome virus isolates. Vet Microbiol 200I, 83:249-263.

10. Zhou YJ, Hao XF, Tian Z], Tong GZ, Yoo D, An TQ, Zhou T, Li GX, Qiu HJ, Wei TC, Yuan XF: Highly virulent porcine reproductive and respiratory syndrome virus emerged in China. Transbound Emerg Dis 2008, 55:152-164.

11. Ropp SL, Wees CE, Fang Y, Nelson EA, Rossow KD, Bien M, Arndt B, Preszler S, Steen P, Christopher-Hennings J, et al.: Characteriza- tion of emerging European-like porcine reproductive and respiratory syndrome virus isolates in the United States. $J$ Virol 2004, 78:3684-3703.

12. Tong GZ, Zhou YJ, Hao XF, Tian ZJ, An TQ, Qiu HJ: Highly pathogenic porcine reproductive and respiratory syndrome, China. Emerg Infect Dis 2007, 13: | 434-1436.

13. Fang Y, Schneider P, Zhang WP, Faaberg KS, Nelson EA, Rowland RR: Diversity and evolution of a newly emerged North American Type I porcine arterivirus: analysis of isolates collected between 1999 and 2004. Arch Virol 2007, 152:1009-1017.

14. Li Y, Wang X, Jiang P, Wang X, Chen W, Wang X, Wang K: Genetic variation analysis of porcine reproductive and respiratory syndrome virus isolated in China from 2002 to 2007 based on ORF5. Vet Microbiol 2009, I38:150-155.

15. Mateu E, Diaz I, Darwich L, Casal J, Martin M, Pujols J: Evolution of ORF5 of Spanish porcine reproductive and respiratory syndrome virus strains from $|99|$ to 2005 . Virus Res 2006, I I 5:198-206.

16. Forsberg R, Storgaard T, Nielsen HS, Oleksiewicz MB, Cordioli P, Sala G, Hein J, Botner A: The genetic diversity of European type PRRSV is similar to that of the North American type but is geographically skewed within Europe. Virology 2002, 299:38-47.

17. Stadejek T, Stankevicius A, Storgaard T, Oleksiewicz MB, Belak S, Drew TW, Pejsak Z: Identification of radically different variants of porcine reproductive and respiratory syndrome virus in Eastern Europe: towards a common ancestor for European and American viruses. J Gen Virol 2002, 83: I86I-I873.

18. Madsen KG, Hansen CM, Madsen ES, Strandbygaard B, Botner A Sorensen KJ: Sequence analysis of porcine reproductive and respiratory syndrome virus of the American type collected from Danish swine herds. Arch Virol 1998, I43:1683-1700.

19. Grebennikova TV, Clouser DF, Vorwald AC, Musienko MI, Mengeling WL, Lager KM, Wesley RD, Biketov SF, Zaberezhny AD, Aliper TI, Nepoklonov EA: Genomic characterization of virulent, attenuated, and revertant passages of a North American porcine reproductive and respiratory syndrome virus strain. Virology 2004, 32 I:383-390.

20. Yang SX, Kwang J, Laegreid W: Comparative sequence analysis of open reading frames 2 to 7 of the modified live vaccine virus and other North American isolates of the porcine reproductive and respiratory syndrome virus. Arch Virol 1998, | 43:60|-6|2.

2I. Goldberg TL, Hahn EC, Weigel RM, Scherba G: Genetic, geographical and temporal variation of porcine reproductive and respiratory syndrome virus in Illinois. J Gen Virol 2000, 8I: 17I-179.

22. Mateu E, Martin M, Vidal D: Genetic diversity and phylogenetic analysis of glycoprotein 5 of European-type porcine reproductive and respiratory virus strains in Spain. J Gen Virol 2003, 84:529-534.

23. Stadejek T, Oleksiewicz MB, Potapchuk D, Podgorska K: Porcine reproductive and respiratory syndrome virus strains of exceptional diversity in eastern Europe support the definition of new genetic subtypes. / Gen Virol 2006, 87: I835-|84I.

24. Thanawongnuwech R, Halbur PG, Ackermann MR, Thacker EL, Royer RL: Effects of low (modified-live virus vaccine) and high (VR2385)-virulence strains of porcine reproductive and respiratory syndrome virus on pulmonary clearance of copper particles in pigs. Vet Pathol 1998, 35:398-406.

Publish with Bio Med Central and every scientist can read your work free of charge

"BioMed Central will be the most significant development for disseminating the results of biomedical research in our lifetime."

Sir Paul Nurse, Cancer Research UK

Your research papers will be:

- available free of charge to the entire biomedical community

- peer reviewed and published immediately upon acceptance

- cited in PubMed and archived on PubMed Central

- yours - you keep the copyright 